\title{
Carbonyl-iron/epoxy composite magnetic core for planar power inductor used in package-level power grid
}

\author{
Yuichiro Sugawa, Kazuma Ishidate, Makoto Sonehara, and Toshiro Sato \\ Spin Device Technology Center, Shinshu University, 4-17-1 Wakasato, Nagano 380-8553, Japan
}

\begin{abstract}
Our research objective is to realize the basic technology for a next generation Package-Level Power Grid (PLPG) for plural application LSIs. In this study, a carbonyl-iron powder (CIP)/epoxy composite magnetic core, for large-current power inductor used for the main dc-dc converter in the PLPG, has been fabricated and evaluated. 54 vol.\%-CIP/epoxy composite core made by screenprinting had a relative permeability of 7.5 and loss tangent of about 0.03 at $100 \mathrm{MHz}$. The planar power inductor using composite core was fabricated and evaluated, which had a quasi closed magnetic circuit consisting of low permeability composite core and embedded $35 \mu \mathrm{m}$ thick, 2-turn copper spiral coil. The fabricated inductor with a $1 \mathrm{~mm}$-square in size had $5.5 \mathrm{nH}$ inductance, $Q$-factor of 15 at 100 $\mathrm{MHz}$ and $18 \mathrm{~m} \Omega$ dc coil resistance. Inductance was constant even when the superimposed dc current increased up to around $5.5 \mathrm{~A}$.
\end{abstract}

Index Terms - Package-level power grid, planar power inductor, carbonyl-iron/epoxy composite magnetic core

\section{INTRODUCTION}

I $n$ the future, monolithic dc-dc converter will be established for a Chip-Level Power-Grid (CLPG), that is, Power Supply on Chip. Research and development of CMOS switch dc-dc converter has been done in order to realize the CLPG [1]-[4], where the power inductor on chip must be realized. P. Hazucha et al. [1] reported the hundreds $\mathrm{MHz}$ switching 90 nm-CMOS switch dc-dc converter using air core chip inductors with $6 \mathrm{nH}$ inductance on package. K. Onizuka et al. [2] developed a CMOS switch buck converter using air core spiral inductor on $\mathrm{Si}$ interposer. Although such air core inductor can be fabricated easily using metal process only, there is serious demerits such as a low inductance, large footprint and undesired EMI noise owing to wide spread alternating magnetic flux. These will be serious obstacles for Power Supply on Chip.

On the other hand, many researchers have tried to establish the power magnetics on chip technology. D. S. Gardner et al. [3] discussed the performance comparison in the various onchip magnetic thin film inductors from the inductance-arealdensity point of view. In order to apply the on-chip magnetic thin film inductor for dc-dc conversion application, the rating current is also important issue. N. Sturcken et al. [4] developed an integrated voltage regulator using coupledmagnetic-core inductor, where they used two sets of four coupled power inductors on Si-interposer. The inductor topology was an elongated spiral with a Ni-Fe magnetic thin film core encasing the copper windings on the long axis. Inverse coupling between adjacent inductors was utilized to avoid magnetic saturation of the core and consequently improved rating current density. We consider it is not so easy to obtain low coil-resistance power inductor on Si-interposer because of a difficulty of very thick conductor process.

We forecast that the next generation power delivery to LSIs will become a Package-Level Power-Grid (PLPG) before

Manuscript received October 31, 2012; revised February 9, 2013 and accepted February 23, 2013. The authors are with the Spin Device Technology Center, Faculty of Engineering, Shinshu University, 4-17-1 Wakasato, Nagano 380-8553, Japan. Corresponding author: Toshiro Sato (email: labyam1@shinshu-u.ac.jp; optional phone: +81-26-269-5184; optional fax: +81-26-269-5215).
CLPG (Power Supply on Chip). Fig. 1 shows an example of PLPG concept. The PLPG will consist of a main dc-dc converter with large current inductor and Point-of-Load (POL) dc-dc converter for each application LSI. The POL converter will have an embedded magnetics in package, semiconductor switches and control circuit. In order to realize the embedded power magnetics, we have developed a Zn-ferrite planar power inductor embedded in plastic interposer package [5]-[8].

As shown in Fig. 1, in order to establish the PLPG, a largecurrent inductor will be required for the main dc-dc converter, which will be mounted on the package because of relatively thick shape to realize the low dc resistance by using very thick coil. We consider that the metal-composite magnetic core made by screen printing is suitable for large current inductor because its low permeability contributes toward larger margin for magnetic core saturation and it can be easily fabricated using low cost screen printing method.

In this study, in order to develop the composite magnetic core used for large-current inductor mounted on package, a carbonyl-iron powder (CIP) has been introduced and applied to the CIP/epoxy composite core.

\section{CARBONYL-IRON/EPOXY COMPOSITE CORE}

\section{A. Carbonyl-iron powder (CIP)}

Carbonyl-iron powder (CIP) made by BASF Co. [9] was used for the starting material for composite core. The CIP was produced by thermal decomposition of iron-pentacarbonyl $\left(\mathrm{Fe}(\mathrm{CO})_{5}\right)$, which was previously distilled to high purity. The CIP used was "Hard Grades", which was an as-decomposited powder without non-reduction. Typical specifications of the CIP are shown in Table 1. BASF Co. showed that the nonreduction CIP has an onion-skin structure [9], which may be due to the spherical iron layers form on a nucleus in the Feparticle growth. Fig. 2 shows the particle-size distribution and SEM image of the CIP, it exhibited a narrow particle-size

Table 1 Typical specifications of Carbonyl-iron powder (CIP).

\begin{tabular}{|c|c|}
\hline Composition wt.\% [9] & $\begin{array}{l}\text { Fe content ; up to } 97.8 \%, \mathrm{C} ; 1.0 \%_{\max } \text {, } \\
\mathrm{N} ; 0.9 \%_{\text {max. }}, \mathrm{O} ; 0.5 \%_{\max }\end{array}$ \\
\hline Mean diameter [9] & $1.1 \mu \mathrm{m}$ \\
\hline Saturation magnetization & $2 \mathrm{~T}$ (measured using VSM) \\
\hline Coercive force & $1 \mathrm{kA} / \mathrm{m}$ (12.5 Oe, measured using VSM) \\
\hline
\end{tabular}




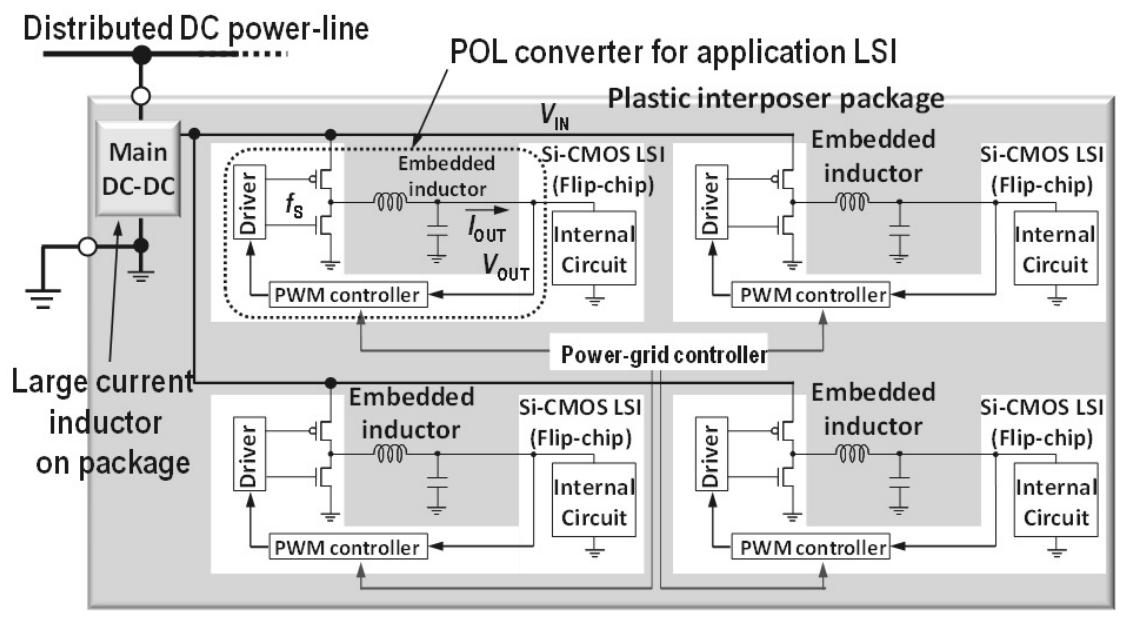

Fig. 1 Package-Level Power-Grid concept.

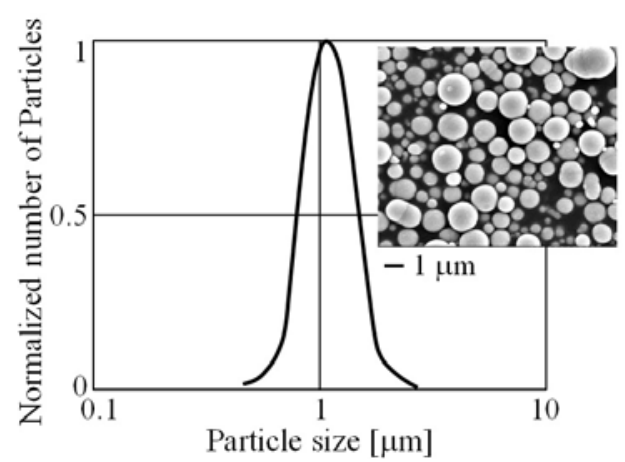

Fig. 2 Particle-size distribution of carbonyl-iron powder (CIP) [9].

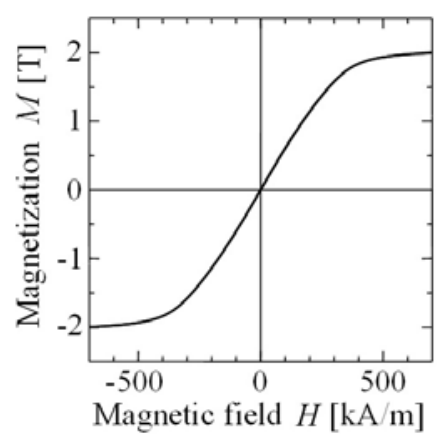

Fig. 3 Static magnetization curve of carbonyl-iron powder (CIP).

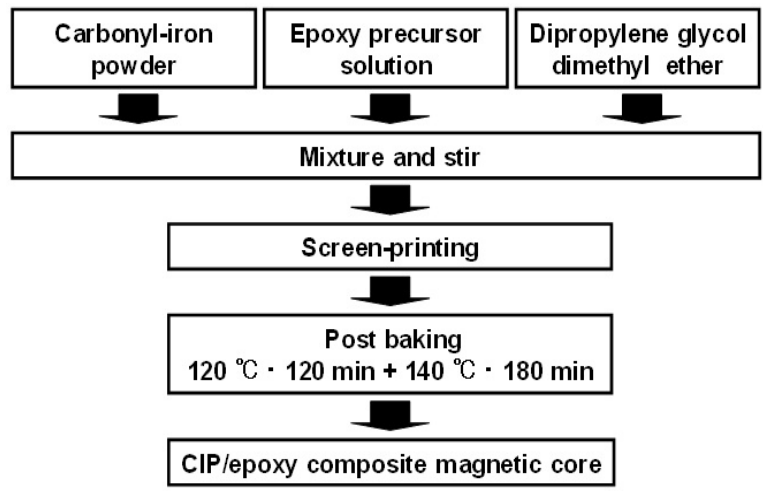

Fig. 4 Fabrication procedure of CIP/epoxy composite core.

distribution with a mean diameter of $1.1 \mu \mathrm{m}$.

M. Koeda et al. [10] investigated the CIP in detail. From the Scanning Transmission Electron Microscopy observation, it was found that the non-reduction CIP consists of $20 \mathrm{~nm}$-size fine grains. Such fine-grain nanostructure causes small crystalline magnetic anisotropy [11]. From the Electron Beam Holography technique, it was found that the non-reduction CIP has a rotational magnetic moment distribution structure (curling magnetic structure). Such magnetic structure causes small magneto-static energy.

Fig. 3 shows the static magnetization curve of the CIP measured using a vibrating sample magnetometer (RIKEN DENSHI; BHV-55). The CIP had a saturation magnetization of about $2 \mathrm{~T}$ and small coercive force. Such small coercive force maybe due to small crystalline magnetic anisotropy based on the fine grain nanostructure .

\section{B. Carbonyl-iron/epoxy composite core}

When making the composite paste composed of the CIP and epoxy precursor solution, the composite paste is expected to have good CIP-dispersion inside the epoxy precursor solution because of small magneto-static coupling between adjacent powders with small magneto-static energy.

Fig. 4 shows the composite core fabrication procedure. The CIP and epoxy precursor solution were mixed and then stirred up using planetary rotating stirrer machine. In order to obtain composite core with different CIP volume fraction, some composite pastes with different ratio of CIP and epoxy precursor solution were prepared. The composite paste was printed using screen mask and then fired at 120 and 140 degree $\mathrm{C}$ in air. The viscosity of the CIP composite paste increased with increasing CIP volume fraction, and it was difficult to print the paste uniformly. Therefore $54 \%$-CIP volume fraction in the post-fired composite core was an upper limit when using the screen printing method.

The square shape composite core was used for the magnetization measurement, and the ring shape core was used for the measurement of complex permeability $v s$. frequency.

\section{Magnetic properties of composite core}

Three kinds of CIP composite cores with $47 \%, 51 \%$ and $54 \%$-CIP volume fraction were fabricated. Fig. 5 shows the static magnetization curve and complex permeability vs. frequency of CIP/epoxy composite core with different CIP volume fraction. In Fig. 5(a), the CIP volume fraction was calculated on the basis of simple magnetization dilution due to 


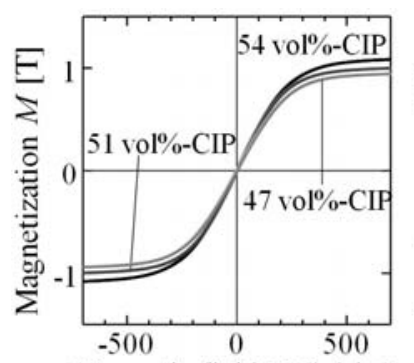

Magnetic field $H[\mathrm{kA} / \mathrm{m}]$

(a) Static magnetization curve

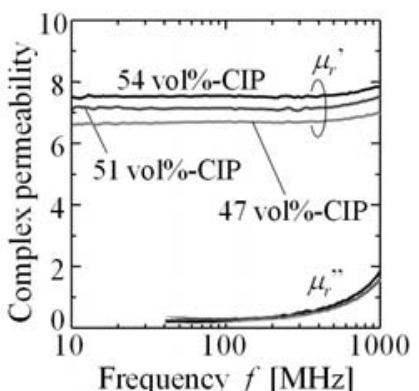

(b) Complex permeability
Fig. 5 Static magnetization curve and complex permeability vs. frequency of CIP/epoxy composite core with different CIP volume fraction.

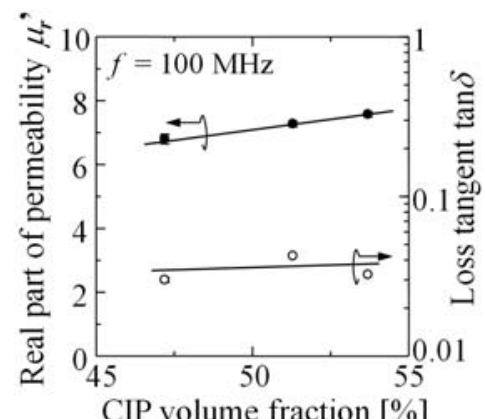

Fig. 6 Relation between permeability, loss tangent and CIP volume fraction of CIP/epoxy composite core ( $f=100 \mathrm{MHz}$ ).

non-magnetic epoxy resin. For example, 54 vol.\%-CIP/epoxy composite core had a saturation magnetization of $1.08 \mathrm{~T}$ and small coercive force of about $2 \mathrm{kA} / \mathrm{m}$ (25 Oe). In Fig. 5(a), "constant susceptibility” was observed even when increasing magnetic field up to around $80 \mathrm{kA} / \mathrm{m}$ (1 kOe). Such constant susceptibility may be due to the distributed air gap (nonmagnetic epoxy resin).

Fig. 5(b) shows the complex permeability vs. frequency of three kinds of the CIP/epoxy composite cores. The initial complex permeability was measured using a material impedance analyzer (HP4291A) with coaxial waveguide testfixture. In the figure, real part of initial relative permeability in each sample was below 10 and nearly constant up to around $500 \mathrm{MHz}$. Loss tangent $\mu_{r}$ '” $/ \mu_{r}$ ' was about 0.2 even at $1 \mathrm{GHz}$.

\section{CIP volume fraction dependence of permeability and loss tangent}

Fig. 6 shows the relation between real part of initial relative permeability, loss tangent and CIP volume fraction of the composite core, which were measured at $100 \mathrm{MHz}$. The initial relative permeability increased slightly up to 7.5 with increasing CIP volume fraction from 47 to $54 \%$. Loss tangent at $100 \mathrm{MHz}$ was around $0.03-0.04$ and its CIP volume fraction dependence was relatively small.

As already reported [5], Fe-based amorphous/polyimide composite core for planar inductor was fabricated, which consisted of $2.6 \mu \mathrm{m}$ size Fe-Si-B-Cr amorphous powder and polyimide. 50 vol.\%-amorphous composite had a loss tangent of about 0.08 at $100 \mathrm{MHz}$. If the high frequency loss of the composite core is dominated by eddy current inside the magnetic metal powder, loss tangent can be written as follows;

$$
\tan \delta=K d^{2} / \rho
$$

where $d$ and $\rho$ are the diameter and electrical resistivity of magnetic particle, $K$ is a constant related to frequency and spherical shape. When both spherical CIP and Fe-based amorphous are exposed to the same frequency magnetic field, $K_{\mathrm{CIP}}$ and $K_{\mathrm{AMO}}$ are identical. From the diameter and resistivity of CIP and Fe-based amorphous particle; $d_{\mathrm{CIP}}=1.1 \mu \mathrm{m}, \rho_{\mathrm{CIP}}=$ $10^{-7} \Omega \mathrm{m}$ in CIP, $d_{\text {AMO. }}=2.6 \mu \mathrm{m}, \rho_{\text {AMO. }}=1.3 \times 10^{-6} \Omega \mathrm{m}$ in Febased amorphous powder, $\tan \delta_{\mathrm{AmO}}$. is calculated to be half of $\tan \delta_{\text {CIP. }}$. From the experimental result shown in Fig. 6, 50 vol.\%-CIP/epoxy composite core is estimated to have $\tan \delta_{\mathrm{CIP}}$ of 0.03 at $100 \mathrm{MHz}$. On the other hand, $\tan \delta_{\mathrm{AMO}}$ of same vol.\% Fe-based amorphous composite core was 0.08 , which is 2.7 times larger than that of CIP composite core. It was considered that the Fe-based amorphous composite has the cluster consisting of plural amorphous particles, hence the eddy current flowing inside large cluster causes larger high frequency loss. Since the CIP composite core has good CIPdispersion in the epoxy resin, the high frequency loss may be due to the eddy current inside the iron particle.

\section{PLANAR POWER INDUCTOR USING COMPOSITE CORE}

\section{A. Planar power inductor structure}

A planar power inductor with $1 \mathrm{~mm}$-square in size was fabricated on a glass-substrate using 54 vol.\%-CIP/epoxy composite core. Fig. 7 shows the schematic view and crosssectional SEM image of the fabricated planar power inductor. As shown in Fig. 7(a), a $35 \mu \mathrm{m}$ thick, 2-turn electroplated copper spiral coil with an $880 \mu \mathrm{m}$-square in size was arranged

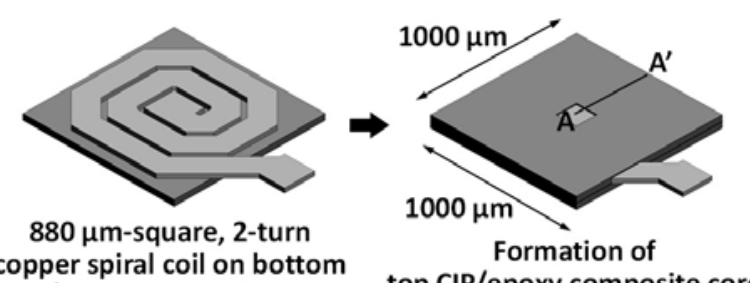
copper spiral coil on bottom top CIP/epoxy composite core
CIP/epoxy composite core

(a) Schematic view

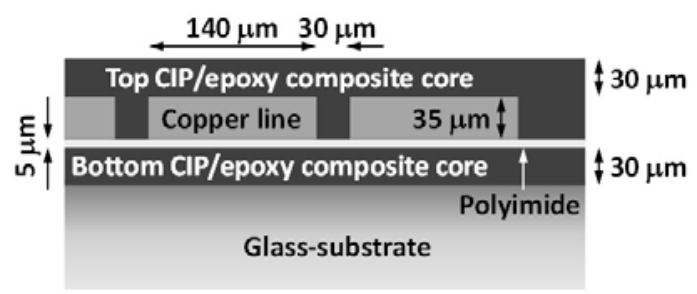

(b) Schematic A-A' cross-section

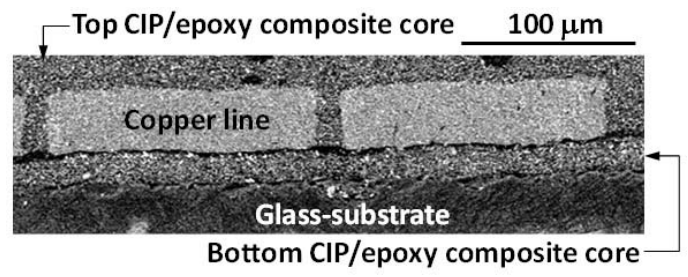

(c) Cross-sectional SEM image

Fig. 7 Schematic view and cross-sectional SEM image of fabricated planar power inductor with 54 vol.\%-CIP/epoxy composite core and 35 $\mu \mathrm{m}$ thick electroplated copper 2-turn spiral coil. 


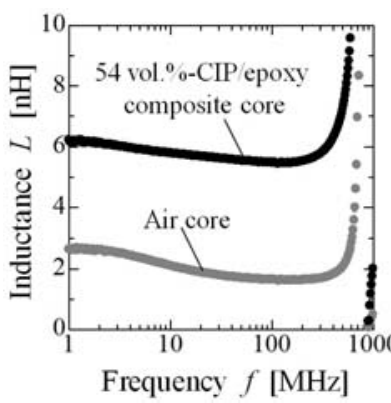

(a) Inductance $v s$. frequency

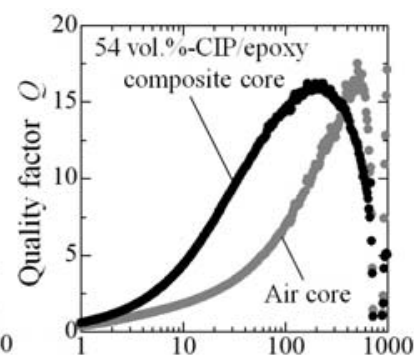

Frequency $f[\mathrm{MHz}]$

(b) $Q$-factor vs. frequency

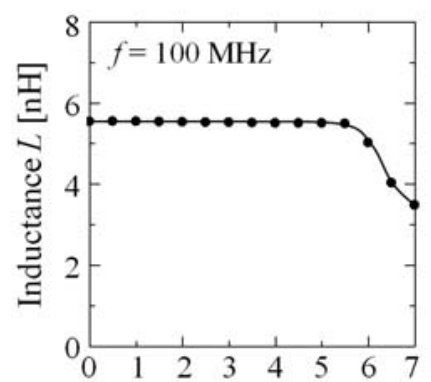

Superimposed dc current $I_{d c}$ [A]

(c) Superimposed dc current characteristic

Fig. 8 Electrical characteristics of the planar power inductor fabricated.

on a bottom $30 \mu \mathrm{m}$ thick composite core made by screenprinting method. In order to planarize the rough surface of the bottom composite core, low-temperature (180 degree-C) fired $5 \mu \mathrm{m}$ thick polyimide under layer for copper spiral coil was used. As shown in Fig.7 (b) and (c), the top composite core was formed directly on the spiral coil and filled in the spacing between thick conductor lines. Hence the fabricated planar power inductor had a quasi closed magnetic circuit consisting of an embedded thick copper spiral coil in the low permeability composite core and polyimide air gap.

\section{B. Electrical characteristics of planar power inductor}

Fig. 8(a), (b) and (c) show the electrical characteristics of the planar power inductor fabricated. Result of air core 2-turn spiral inductor is also shown. In Fig. 8(a), the composite core inductor had $5.5 \mathrm{nH}$ inductance at $100 \mathrm{MHz}$, which was 3.7 times larger than that of air core inductor. Resonant frequency was about $600 \mathrm{MHz}$, which was slightly lower than that of air core spiral. In Fig. 8(b), Q-factor of the composite core inductor was 15 at $100 \mathrm{MHz}$, which was 2.4 times higher than that of air core spiral. The dc coil resistance $R_{d c}$ was about 18 $\mathrm{m} \Omega$, which was close to the calculated value of $16 \mathrm{~m} \Omega$ on the basis of designed parameters of copper spiral coil.

Fig. 8(c) shows the superimposed dc current characteristic of the fabricated composite core inductor. Inductance was constant even when the superimposed dc current increased up to around 5.5 A. Such excellent superimposed dc current characteristic is mainly due to the "constant permeability" of the CIP/epoxy composite core.

\section{CONCLUSIONS}

$1.1 \mu \mathrm{m}$ size carbonyl-iron powder (CIP)/epoxy composite core, for large-current power inductor used for main dc-dc converter in the Package-Level Power Grid, has been fabricated and evaluated. 54 vol.\%-CIP/epoxy composite core had a relative permeability of 7.5 and loss tangent of about 0.03 at $100 \mathrm{MHz}$. The CIP/epoxy composite core had "constant permeability" even when increasing magnetic field up to $80 \mathrm{kA} / \mathrm{m}$ (1 kOe). Such constant permeability may be due to the distributed air gap (non-magnetic epoxy resin).

As a first trial application, a planar power inductor with 1 mm-square in size has been fabricated using 54 vol.\% CIP /epoxy composite core. The fabricated composite core inductor had $5.5 \mathrm{nH}$ inductance, $Q$-factor of 15 at $100 \mathrm{MHz}$ and $18 \mathrm{~m} \Omega \mathrm{dc}$ resistance. In the superimposed dc current characteristic, inductance was constant even when the superimposed dc current increased up to around 5.5 A.

\section{ACKNOWLEDGEMENT}

This work was supported in part by a Grant-in-Aid for Scientific Research of Japan Society for the Promotion of Science (JSPS), No. 24560328.

\section{REFERENCES}

[1] P. Hazucha, G. Schrom, J. Hahn, B. A. Bloechel, P. Hack, G. E. Dermer, S. Narendra, D. Gardner, T. Karnik, V.De, and S. Borkar, “A 233-MHz 80\%-87\% Efficient Four-Phase DC-DC Converter Utilizing Air-Core Inductors on Package”, IEEE Journal of Solid-State Circuit, Vol.40 , No.4, pp.838-845 (2005).

[2] K. Onizuka, K. Inagaki, H. Kawaguchi, M. Takamiya, and T. Sakurai, "Stacked-Chip Implementation of On-Chip Buck Converter for Distributed Power Supply System in SiPs”, IEEE Journal of Solid-State Circuits, Vol. 42, NO. 11, pp. 2404-2410 (2007).

[3] D. S. Gardner, G. Schrom, F. Paillet, B. Jamieson, T. Karnik, and S. Borkar, "Review of On-Chip Inductor Structures with Magnetic Films", IEEE Transactions on Magnetics, Vol.45, No.10, pp.4760-4766 (2009).

[4] N. Sturcken, E. O’Sullivan, N. Wang, P. Herget, B. Webb, L. Romankiw, M. Petracca, R. Davies, R. Fontana, G. Decad, I. Kymissis, A. Peterchev, L. Carloni, W. Gallagher, K. Shepard, "A 2.5D Integrated Voltage Regulator Using Coupled-Magnetic-Core Inductors on Silicon Interposer Delivering 10.8A $/ \mathrm{mm}^{2}$,, Digest of Technical Papers, 2012 IEEE International Solid-State Circuits Conference, 23.1, pp.400-402 (2012).

[5] H. Ito, A. Takeuchi, S. Okazaki, H. Kobayashi, Y. Sugawa, A. Takeshima, M. Sonehara, N. Matsushita, T. Sato, "Fabrication of Planar Power Inductor for Embedded Passives in LSI Package for Hundreds Megahertz Switching DC-DC Buck Converter", IEEE Transactions on Magnetics, Vol.47, No.10, pp.3204-3207 (2011).

[6] T. Fujii, K. Kobayashi, H. Shimizu, S. Nakazawa, T. Sato, F. Sato, H. Kobayashi, "Planar Power Inductor with Magnetic Film for Embedded LSI Package”, 45th International Symposium on Microelectronics 2012 (IMAPS2012), TP6, San Diego, USA (Sept.9-13, 2011).

[7] T. Sato, M. Sonehara, K. Ikeda, H. Nakayama, K. Takizawa, "Development of Micro Magnetic Devices for High-Frequency Power Conversion and RF Applications", International Conference of the Asian Union of Magnetics Societies, Nara, Japan, 5aB-3 (Oct.2-5, 2012).

[8] T. Sato, M. Sonehara, H. Kobayashi, F. Sato, K. Hagita, R. Takeda, N. Matsushita, T. Fujii, S. Nakazawa, H. Shimizu, K. Kobayashi, Y. Shinozuka, H. Fuketa, M. Takamiya, T. Sakurai, "Magnetic core power inductor embedded in plastic interposer toward power supply integrated in LSI Package", The 3rd International Workshop on Power Supply on Chip (PowerSoC2012), San Francisco, USA, S-7-2 (Nov.16-18, 2012).

[9] http://www.inorganics.basf.com/ca/internet/en/content/Produkte/Metalls ysteme/CIP/CIP

[10] M. Koeda, A. Harada, H. Ono, T. Ishikura, T. Kuroda, H. Moro, "Research of Carbonyl Iron Powder for Development of the Power Inductor for High Frequency", IEEJ Transactions on Fundamentals and Materials, Vol.131, No.11, pp.949-954 (2011) (in Japanese).

[11] G. Herzer, "Grain size dependence of coercivity and permeability in nanocrystalline ferromagnets”, IEEE Transactions on Magnetics, Vol.26, No.5, pp.1397-1402 (1990). 